\title{
Macrophages participate in local and systemic inflammation induced by amorphous silica nanoparticles through intratracheal instillation
}

This article was published in the following Dove Press journal:

International Journal of Nanomedicine

22 November 2016

Number of times this article has been viewed

\author{
Man Yang ${ }^{1,2}$ \\ Li Jing ${ }^{1,2}$ \\ Ji Wang ${ }^{1,2}$ \\ Yang $\mathrm{Yu}^{1,2}$ \\ Lige Cao ${ }^{1,2}$ \\ Lianshuang Zhang ${ }^{1,2}$ \\ Xianqing Zhou ${ }^{1,2}$ \\ Zhiwei Sun ${ }^{1,2}$
}

'School of Public Health, Capital Medical University, Beijing, People's

Republic of China; ${ }^{2}$ Beijing Key

Laboratory of Environmental

Toxicology, Capital Medical University,

Beijing, People's Republic of China
Correspondence: Zhiwei Sun

Department of Toxicology and Hygienic

Chemistry, School of Public Health,

Capital Medical University, No $10 \mathrm{Xi}$

Tou Tiao, You An Men, Beijing, 100069,

People's Republic of China

Tel +86 1083911507

Email zwsun@hotmail.com

\begin{abstract}
Silica nanoparticles (SiNPs) are amongst the most commonly used materials in the field of nanomedicine and, therefore, their influence on organisms has drawn increasing attention in recent years. Most reports have focused on the single tissue reactions induced by SiNPs. Herein, the reaction of primary organs to SiNPs following intratracheal instillation in mice was analyzed by histopathology and ultrastructure observation. Following elucidation of the role of macrophages in local and systemic inflammation, the underlying mechanisms were explored using a macrophage cell line in vitro. The results suggest that macrophages swallow the SiNPs and secrete inflammatory factors by activating the NLRP3 inflammasome, thus participating in local and systemic inflammation.
\end{abstract}

Keywords: silica nanoparticles, inflammation, macrophages, organs, NLRP3 inflammasome

\section{Introduction}

Silica nanoparticles (SiNPs) are amongst the most widely employed nanomaterials, with applications in cosmetics and food additives, drug delivery, printer toner, and paint, among others. Previous studies analyzing the global life cycle release of engineered nanomaterials found that SiNPs dominate the market. ${ }^{1}$ Therefore, human exposure to SiNPs is widespread, including due to environmental, occupational, indoor fuel burning, and iatrogenic exposure. The International Agency for Research on Cancer (IARC) classified amorphous silica as a group 3 (inadequate evidence for carcinogenicity) material in 1977 and crystal silica as a group 1 (carcinogenic to humans) material in 2012. ${ }^{2}$ There is little evidence for the evaluation of SiNPs. The organization of Economic Cooperation and Development have included SiNPs on the priority list for toxicity evaluation. ${ }^{3}$

Inhalation is one of the main human exposure pathways of SiNPs, with possible lung inflammation or damage. ${ }^{4-6}$ SiNPs have a small size and a large surface area, and may therefore induce greater toxicity than crystal silica. In 2007, Napierska et al ${ }^{7}$ reviewed the available literature regarding in vivo and in vitro interactions of SiNPs with biological systems, and found that SiNP inhalation may lead to lung inflammation, granuloma formation, and emphysema. Most in vitro studies found that SiNPs can cause oxidative stress, cell membrane damage, cell toxicity, and early inflammatory response. ${ }^{8-10}$ Maser et $\mathrm{al}^{6}$ found that within 3 days after single intratracheal instillation, $\mathrm{SiO}_{2}$ nanoparticles caused genotoxic effects in the rat lung and bone marrow. Further, some studies indicated cardiovascular toxicity of amorphous SiNPs. ${ }^{11,12}$ Nevertheless, the response of other organs following inhalation of SiNPs remains poorly understood. 
Despite there being sufficient epidemiological evidence regarding the influence of particle matter on the pulmonary and cardiovascular systems, the effects in other organs remain underreported, especially with regard to multiorgan toxicity from a single nanoparticle type. Hepatotoxicity following intravenous injections of SiNPs has been observed, as expected, because the liver is the primary organ for toxin biotransformation. ${ }^{13-15} \mathrm{Li}$ et a ${ }^{16}$ found that acute oral administration of mesoporous SiNPs led to renal damage. Further, the intraperitoneal treatment of amorphous SiNPs probably induced inflammation and DNA damage in the lung, heart, liver, kidney, and brain. ${ }^{17}$ Most of the studies were concerned with the acute toxicity.

This study assesses the influence of SiNPs on various tissues following exposure through the respiratory pathway in vivo. Histopathologic and morphologic changes in primary organs in mice following intratracheal instillation of SiNPs were analyzed and inflammation factors in peripheral blood serum were quantified to assess the degree of systemic inflammation. Further, clinical chemistry parameters were used to assess the impairment of liver and kidney function induced by SiNPs. Following confirmation of the participation of macrophages in all organs, in vitro analyses were performed using the mouse macrophage cell line RAW264.7 to explore the tissue inflammation mechanisms induced by SiNPs.

\section{Materials and methods SiNP synthesis}

SiNPs were synthesized through the Stöber method. Briefly, $2.5 \mathrm{~mL}$ of tetraethyl orthosilicate (TEOS) was added to $50 \mathrm{~mL}$ of a premixed ethanol solution containing $2 \mathrm{~mL}$ of ammonia and $1 \mathrm{~mL}$ of water. The mixture was kept at $40^{\circ} \mathrm{C}$ for $12 \mathrm{~h}$ with continuous stirring $(150 \mathrm{rpm})$ and was then centrifuged at $12,000 \mathrm{rpm}$ for $15 \mathrm{~min}$ to isolate the particles. The particles were washed three times with deionized water and dispersed in deionized water as a concentrated suspension for further experiments.

\section{SiNP quantification}

Two methods were used to confirm the concentration of the SiNP suspension. The first followed the traditional method of placing $1 \mathrm{~mL}$ of suspension in a $\mathrm{n}$ electric thermostatic drying oven and weighing the sample every $4 \mathrm{~h}$ until no further changes in weight were observed. The second method involved thermogravimetric analysis (using a Thermogravimetric Analyzer Q600; TA Instruments, New Castle, DE, USA) to investigate the weight change kinetics of SiNPs under a nitrogen atmosphere using both a ramp mode (ramp $10^{\circ} \mathrm{C} / \mathrm{min}$ to $110^{\circ} \mathrm{C}, \mathrm{N}_{2}$ flow $40 \mathrm{~mL} / \mathrm{min}$, platinum pans) and an isothermal mode (heating $20^{\circ} \mathrm{C} / \mathrm{min}$, from room temperature to specified isothermal temperature and then isothermal for 1 h, $\mathrm{N}_{2}$ flow $40 \mathrm{~mL} / \mathrm{min}$, platinum pans, isothermal temperature interval $20^{\circ} \mathrm{C}$ ).

\section{SiNP characterization}

SiNP suspensions were dispersed with a sonicator (Bioruptor UDC-200; Diagenode, Liège, Belgium) for $5 \mathrm{~min}$ prior to use. Transmission electron microscopy (TEM, JEOL JEM2100; JOEL Ltd., Akishima-shi, Japan) was used to assess the particle size and morphology. A Zetasizer (Nano-ZS90; Malvern, Worcestershire, UK) was applied to measure the hydrodynamic size distribution and zeta potential of SiNP suspensions. Inductively coupled plasma-atomic emission spectrometry (ICP-AES, ARL 3520; ARL, Washington, DC, USA) was used to determine the purity of SiNPs. The limulus amebocyte lysate assay was used to test the endotoxicity of SiNPs.

\section{Animal experiments}

Female Balb/c mice ( 8 weeks old, 20-22 $\mathrm{g}$ in body weight) were purchased from Weitong-Lihua Experimental Animal Center (Beijing, People's Republic of China) and raised in specific pathogen free (SPF)-class animal room maintained at $20^{\circ} \mathrm{C} \pm 2{ }^{\circ} \mathrm{C}$ and $60 \% \pm 10 \%$ relative humidity with a $12 \mathrm{~h}$ lightdark cycle. All animal experiments followed the national guidelines for animal care and use, and were approved by the Animal Ethics Committee at Capital Medical University (Ethical code was AEEI-2015-103). Mice were divided into four groups at random and fasted overnight prior to the administration of SiNPs. The applied dosages of SiNPs were 0, 7, 21 , and $35 \mathrm{mg} / \mathrm{kg}$, according to the WHO clean air standards, the respiratory rate and respiratory capacity of mice, and the safety coefficient from experimental animals extrapolated to humans. The concentrated SiNPs were diluted in physiological saline and administered to the mice by intratracheal instillation once every 3 days for a total of five intratracheal instillations. One day following the final administration, the animals were sacrificed for subsequent study.

\section{Histopathology}

The tissue samples were fixed in $10 \%$ formalin, embedded in paraffin, sectioned, and stained with hematoxylin and eosin for histological observation with an optical microscope (Olympus X71-F22PH; Tokyo, Japan).

\section{TEM observation}

The samples were collected and immediately fixed in 3\% glutaraldehyde for $4 \mathrm{~h}$ and then washed three times with $0.1 \mathrm{M}$ phosphate-buffered saline (PBS) and post-fixed with 
$1 \%$ osmic acid for $2 \mathrm{~h}$. After three rinses with $0.1 \mathrm{M}$ PBS and serial dehydration with $50 \%, 70 \%, 80 \%, 90 \%$, and $100 \%$ alcohol and $100 \%$ acetone, the samples were embedded in epoxy resin. Ultrathin sections $(50 \mathrm{~nm})$ were obtained using an ultramicrotome (Ultra cut UCT; Leica, Wetzlar, Germany). The sections were stained with lead citrate and uranyl acetate, and imaged using TEM.

\section{Immunohistochemistry}

Following deparaffinization and rehydration, the sections were boiled in $10 \mathrm{mM}$ sodium citrate buffer $(\mathrm{pH}$ 6.0) and maintained at a sub-boiling temperature for $10 \mathrm{~min}$. The samples were then blocked with $10 \%$ normal goat serum for $10 \mathrm{~min}$ and incubated overnight at $4{ }^{\circ} \mathrm{C}$ with primary antibody (F4/80). Following treatment with the avidin-biotin affinity system (30 min, room temperature) and staining with the substrate, the sections were examined under an optical microscope.

\section{Bead-based multiplex flow cytometry}

The cytokine expression of four different inflammatory factors (interleukin (IL)-1 $\beta$, IL-18, tumor necrosis factor (TNF)- $\alpha$, and IL-6) was determined in the serum of mice peripheral blood using the Aimplex ${ }^{\circledR}$ bead-based immunoassay kit. In the multiplex immunoassay, the bead populations were differentiated by size and level of fluorescence intensity. The beads were coated with capturing antibodies for specific cytokines. The kit was used according to the manufacturer's instructions. Briefly, the beads were incubated with the samples for $60 \mathrm{~min}$, following which the biotinylated antibodies were added and incubated for $30 \mathrm{~min}$ and streptavidin-P-phycoerythrin (PE) was added for a further $20 \mathrm{~min}$ of incubation. Finally, the samples were placed on the flow cytometer (FACSCalibur, 0123456789) to detect the fluorescence signal of the sample beads and the results were analyzed using the FCAP Array software (V3.0).

\section{Clinical chemistry parameters analysis}

The clinical chemistry parameters of liver and kidney function were tested using the standard spectrophotometric methods of a Cobas Integra 400 plus Automatic Biochemistry Analyzer (Roche, Basel, Switzerland).

\section{Cell culture experiments}

Mouse macrophage cell line RAW264.7 was purchased from the Cell Resource Center, Shanghai Institutes for Biological Sciences (SIBS, Shanghai, China). The cells were cultured in Dulbecco's Modified Eagle's Medium (DMEM; Gibco, Grand Island, NY, USA) supplemented with 10\% fetal bovine serum (Gibco, Grand Island, NY,), $100 \mathrm{U} / \mathrm{mL}$ penicillin, and $100 \mu \mathrm{g} / \mathrm{mL}$ streptomycin, and cultured in the cell incubator at $37^{\circ} \mathrm{C}$ in a $5 \% \mathrm{CO}_{2}$ humidified environment.

\section{Cell vitality measurements}

Cells were seeded and cultured in 96-well plates at a density of $10^{4}$ cells $/ \mathrm{mL}$ for $24 \mathrm{~h}$ prior to the experiments. The cells were then treated with $\operatorname{SiNPs}(0,5,10,20$, and $40 \mu \mathrm{g} / \mathrm{mL})$ suspended in serum-free DMEM for $24 \mathrm{~h}$. Each group had six replicate wells. Then, $10 \mu \mathrm{L}$ of cell counting kit- 8 reagent was added to each well for $2 \mathrm{~h}$ at $37^{\circ} \mathrm{C}$ and the optical density at $450 \mathrm{~nm}$ was then detected with a microplate reader (Thermo Multiskan MK3; Waltham, MA, USA).

\section{Cell phagocytic ability assay}

Following incubation with SiNPs of different concentrations for $24 \mathrm{~h}$, a $0.05 \%$ neutral red solution was added to each well for $4 \mathrm{~h}$. The cells were washed three times with PBS. Then, the cell lysis buffer (ethanol:acetic acid 1:1) was added to each well and, after $10 \mathrm{~min}$, the optical density at $520 \mathrm{~nm}$ was detected with a microplate reader.

\section{Western blot analysis}

The Western blot assay was used to detect the expression of the inflammation-associated proteins. The concentration of cellular protein extracts was determined using the bicinchoninic acid protein assay (Pierce, Rockford, IL, USA). Equal amounts of proteins $(20 \mu \mathrm{g})$ were loaded onto an sodium dodecyl sulfate (SDS)-polyacrylamide gel (10\% separation gels) and electrophoretically transferred to a polyvinylidenefluoride membrane (Millipore, Billerica, MA, USA); 5\% nonfat milk in tris-buffered saline (TBS) was applied to block the membrane for $1 \mathrm{~h}$. The membrane was incubated with the primary antibodies (NLRP3, nuclear factor- $\kappa \mathrm{B}, \mathrm{IL}-1 \beta$, and tubulin, 1:1,000 rabbit antibodies; Cell Signaling Technology, Beverly, MA, USA) overnight at $4^{\circ} \mathrm{C}$. The membrane was washed with TBS and Tween 20 (TBST) three times and incubated with a horseradish peroxidaseconjugated anti-rabbit immunoglobulin G secondary antibody (CST, Beverly, MA, USA) for $1 \mathrm{~h}$ at room temperature. After washing three times with TBST, the antibody-bound proteins were detected using enhanced chemiluminescence (Thermo Fisher Scientific, Waltham, MA, USA). Analysis of the protein bands was performed by ImageLab ${ }^{\mathrm{TM}}$ Software (Bio-Rad, Hercules, CA, USA).

\section{Statistical analysis}

The data of all experiments are represented as mean \pm SD, and the significance was calculated with the independent sample 
$t$-test using IBM SPSS Statistic 19 software. The normal distribution of data was tested prior to performing the $t$-test. Differences were considered significant at $P<0.05$.

\section{Results}

\section{SiNP quantification and characterization}

TEM images of SiNPs in deionized water (Figure 1A) and serum-free DMEM medium (Figure 1B) both show that the SiNPs were spherical and uniformly dispersed. Both quantification methods described above led to the same results with regard to the weight of SiNPs in the stock solutions. Figure $1 \mathrm{C}$ shows a decline in weight with time until $\sim 7 \mathrm{~min}$, when the SiNP weight no longer changed. The concentration of the SiNP solutions was calculated, through a combination of the two methods, as $63.19 \mathrm{mg} / \mathrm{mL}$.

The average particle size was $43.11 \pm 5.89 \mathrm{~nm}$ after counting 1,000 particles using ImageJ software (Figure 1D). The purity of the particles, as tested using ICP-AES, was higher than $99.9 \%$. The hydrodynamic diameter and zeta potential were measured in deionized water and serum-free DMEM medium at different times to monitor the dispersion status of SiNPs. The hydrodynamic diameters of SiNPs in water and medium were $\sim 80$ and $90 \mathrm{~nm}$, respectively, and the zeta potentials were highly negatively charged (about $-30 \mathrm{mV}$ ), showing the stability of both dispersion solutions (Table 1).

\section{Observation of ultrastructural changes of the lung, liver, and heart and SiNP location}

TEM images show the SiNP deposition and ultrastructural variation in the various tissues following intratracheal instillation (Figure 2). Most SiNPs were wrapped in lung lysosomes (Figure 2Ab and c) and more secondary lysosomes were observed in the heart and liver (Figure $2 \mathrm{Bb}$ and $\mathrm{Cb}$ ) than the control group (Figure $2 \mathrm{Ba}$ and $\mathrm{Ca}$ ). The mitochondria in the experimental group were swollen and
A

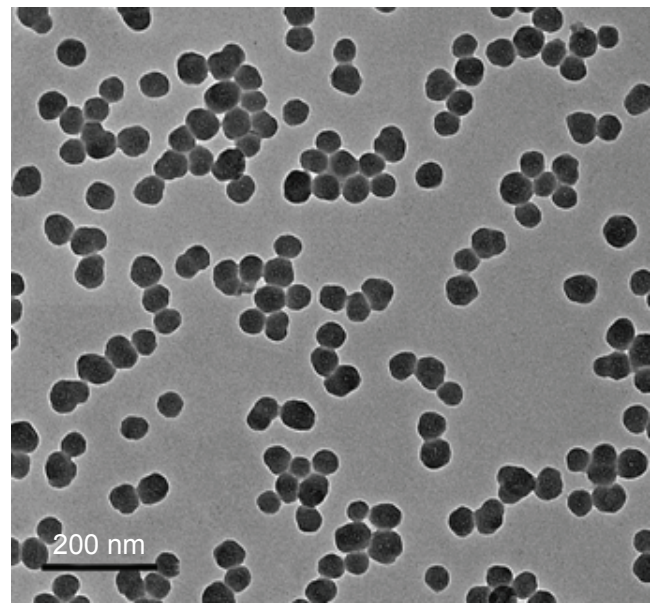

C

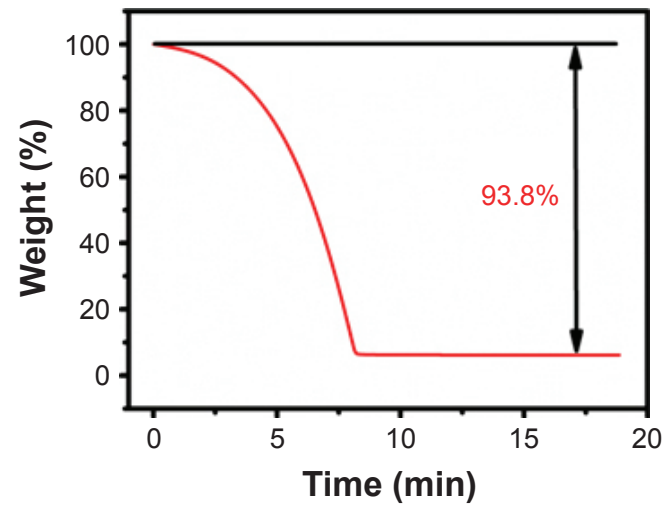

B

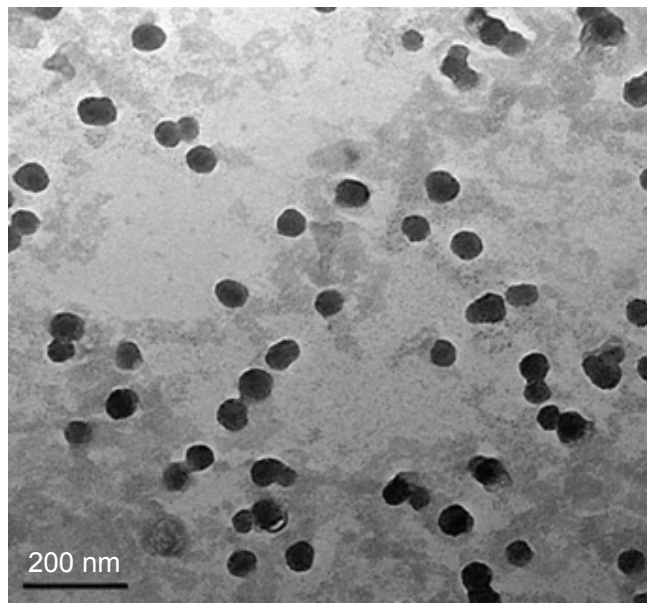

D

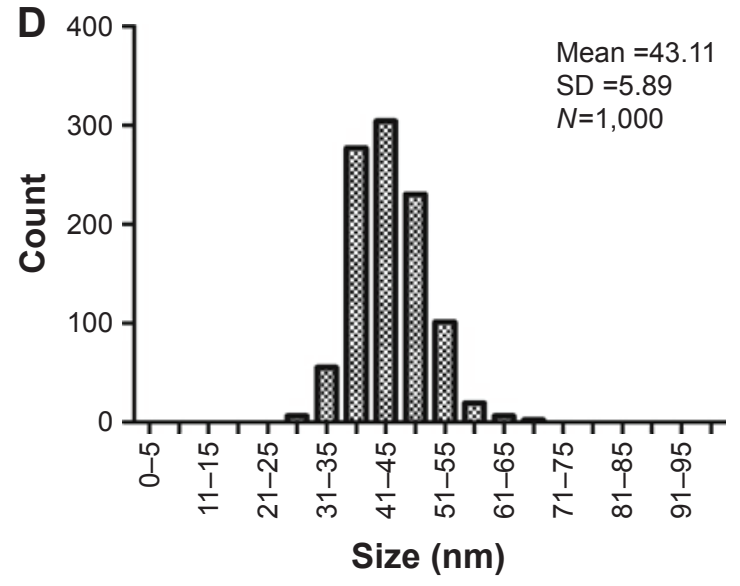

Figure I Characterization of silica nanoparticles (SiNPs).

Notes: (A) Transmission electron microscopy image of SiNPs in deionized water. (B) Transmission electron microscopy image of SiNPs in serum-free Dulbecco's Modified Eagle's Medium. (C) Thermogravimetric analysis of SiNPs. (D) Size distribution of SiNPs calculated using Image Software. SiNPs in both water and medium dispersed stably and had a spherical morphology of $43 \mathrm{~nm}$ in size on average as measured using Image software. 
Table I Hydrodynamic size and zeta potential of silica nanoparticles in dispersion media

\begin{tabular}{|c|c|c|c|c|c|c|}
\hline \multirow{2}{*}{$\begin{array}{l}\text { Time } \\
\text { (day) }\end{array}$} & \multicolumn{3}{|l|}{ Deionized water } & \multicolumn{3}{|c|}{ DMEM without serum } \\
\hline & $\begin{array}{l}\text { Hydrodynamic } \\
\text { size }(\mathrm{nm})\end{array}$ & PDI & $\begin{array}{l}\text { Z-potential } \\
(\mathrm{mV})\end{array}$ & $\begin{array}{l}\text { Hydrodynamic } \\
\text { size }(\mathrm{nm})\end{array}$ & PDI & $\begin{array}{l}\text { Z-potential } \\
(\mathrm{mV})\end{array}$ \\
\hline 0 & 80.66 & 0.124 & -24.7 & 90.57 & 0.186 & -24.7 \\
\hline I & 78.88 & 0.098 & -25.3 & 85.98 & 0.177 & -25.75 \\
\hline 5 & 79.77 & 0.130 & -28.2 & 93.75 & 0.139 & -24.55 \\
\hline 7 & 79.76 & 0.150 & -26.3 & 94.53 & 0.156 & -24.5 \\
\hline 10 & 79.34 & 0.122 & -29.7 & 85.19 & 0.179 & -26.4 \\
\hline 14 & 77.65 & 0.139 & -27.2 & 90.51 & 0.138 & -24.4 \\
\hline 17 & 79.51 & 0.138 & -28.1 & 91.81 & 0.167 & -25.6 \\
\hline 21 & 79.65 & 0.126 & -29.9 & 91.18 & 0.154 & -26.7 \\
\hline 51 & 75.45 & 0.111 & -28.7 & 90.32 & 0.123 & -28.2 \\
\hline
\end{tabular}

Abbreviations: PDI, polydispersity index; DMEM, Dulbecco's Modified Eagle's Medium.

the cristae were disordered, indicating functional impairment of the mitochondria (Figure 2Ac). The SiNPs were located in the cytoplasm rather than in the nucleus. Interestingly, the SiNPs were engulfed by macrophages in the lung and not by other cell types. In the heart and liver, the cells with more secondary lysosomes were also macrophages.

\section{Histologic and immunohistochemical analysis of the tissues}

Compared with the control group (Figure 3Ba-c), SiNPs induced thick septa in the lung (Figure 3Ac), capillary hyperemia, and inflammatory cell infiltration, with several consolidation areas (Figure 3Aa), indicating the deformation
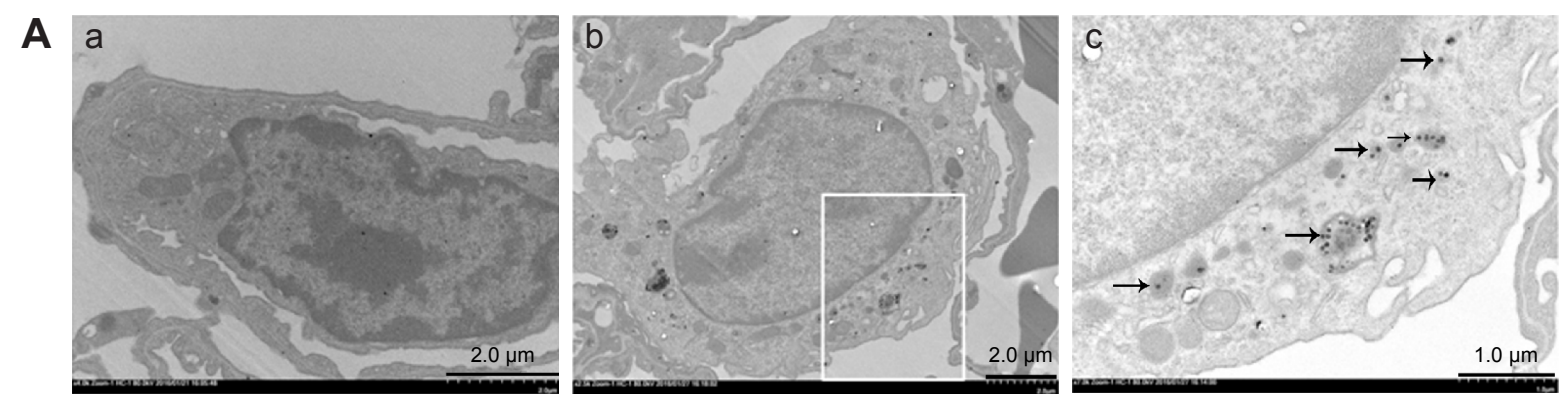

B
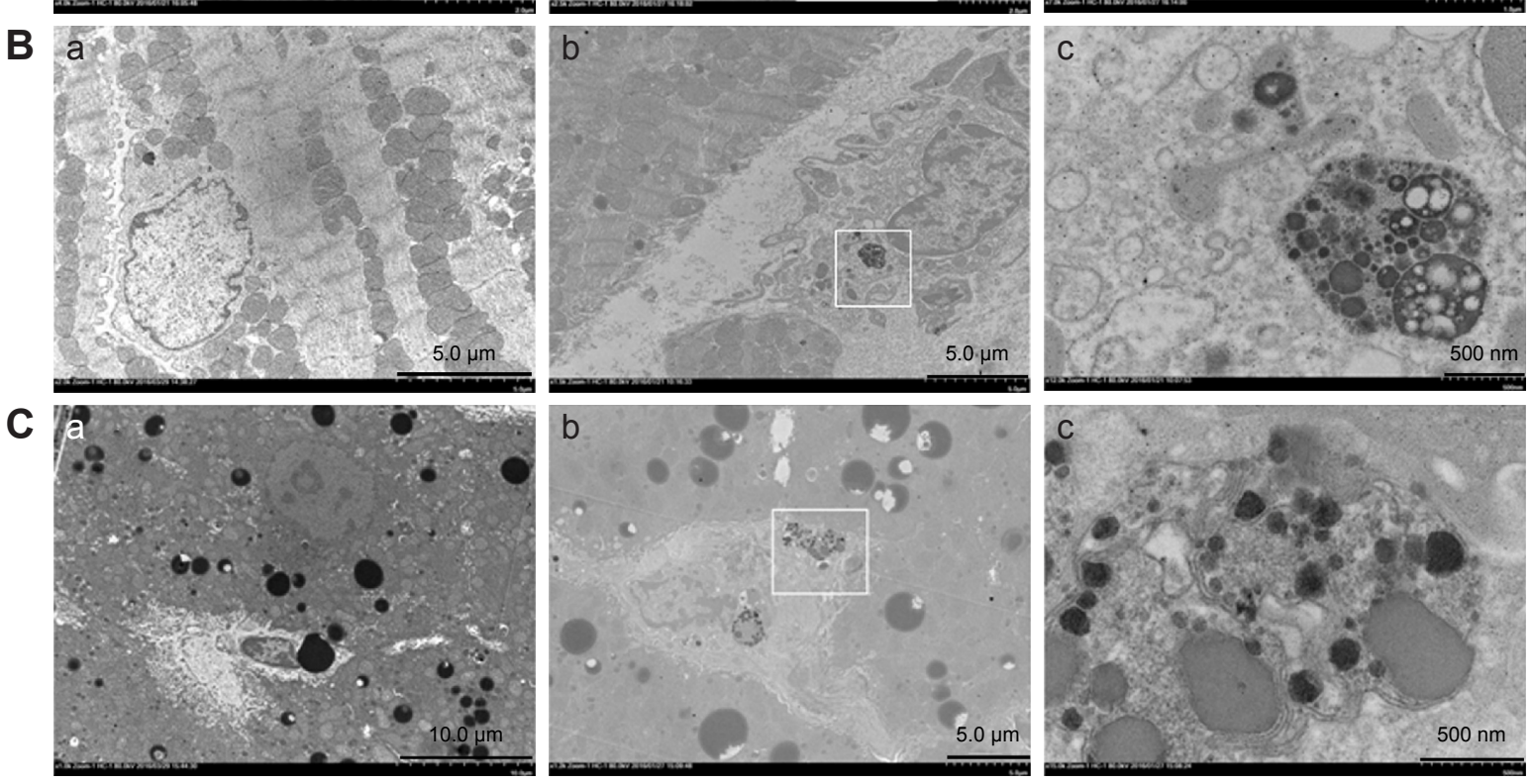

Figure 2 Transmission electron microscopy observation of ultrastructural changes of lung (A), heart (B), and liver (C) induced by silica nanoparticles (SiNPs).

Notes: SiNPs were internalized in the lysosomes (black arrow) or pericytes. The white panes indicate significant areas. (a) Control group (saline treated group); (b) and (c) experimental group (35 mg/kg SiNP dosage group), and (c), the significant areas. 
A

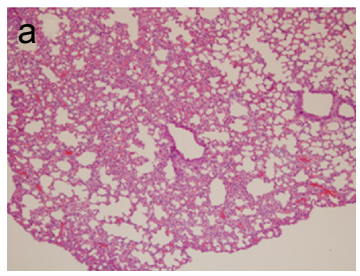

B

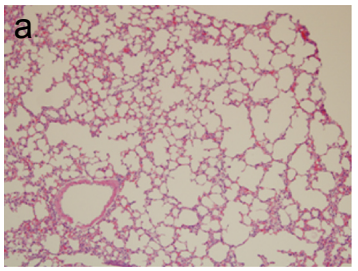

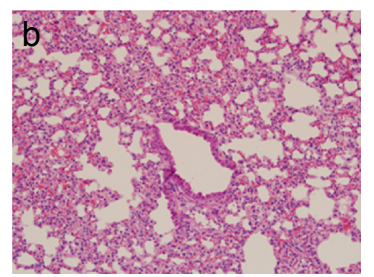
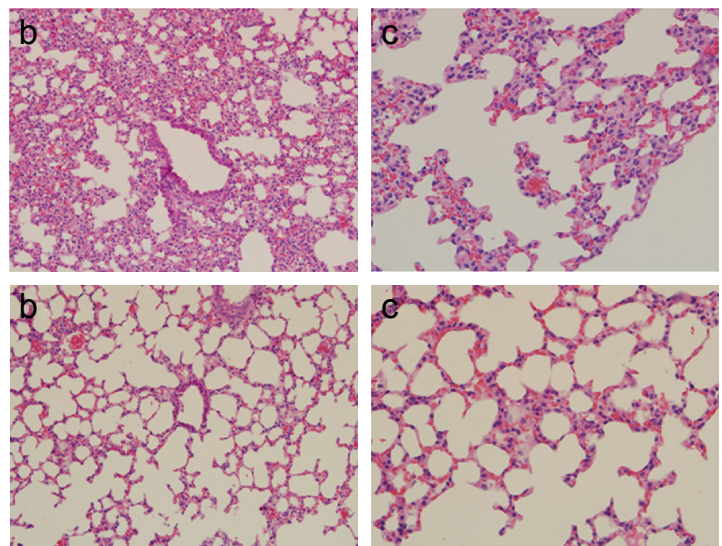

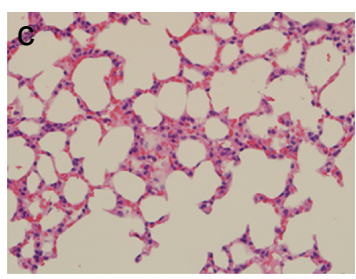

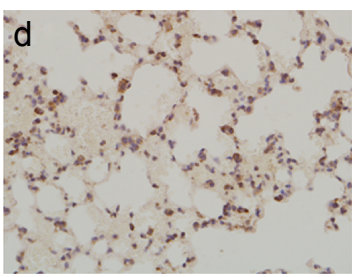

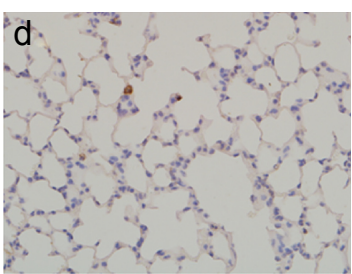

Figure 3 Histological observation $(\mathbf{A a}-\mathbf{c}$ and $\mathbf{B a}-\mathbf{c})$ and immunohistochemical staining (Ad and $\mathbf{B d}$ ) of macrophage surface molecular marker F4/80 in pulmonary tissues sections.

Notes: (A) Experimental group (35 mg/kg dosage group); (B) control group (saline-treated group). Magnifications: (a) I00×; (b) 200×; (c, d) 400x.

of alveolar cells (Figure $3 \mathrm{Ab}$ ) and damage of lung function. In addition, F4/80, a biomarker of macrophage cells, was used to monitor the cell type and macrophage activation in the tissue sections. Compared with the control (Figure 3Bd), the number of F4/80-positive cells increased significantly following the administration of SiNPs (Figure 3Ad).

Pathologic observation of hepatic tissue sections is shown in Figure 4Aa and $\mathrm{b}$, and $\mathrm{Ba}$, indicating diffuse lymphocytic aggregation in the SiNP-treated group (Figure 4A, black arrow) and not in the control group (Figure 4B), thus implying chronic infection and inflammation following treatment with SiNPs. The macrophage-specific marker F4/80 was observed in liver sections by immunohistochemistry. As shown in Figure 4Ac and d, the F4/80-positive cells (white arrow) were prominent in the experimental group.
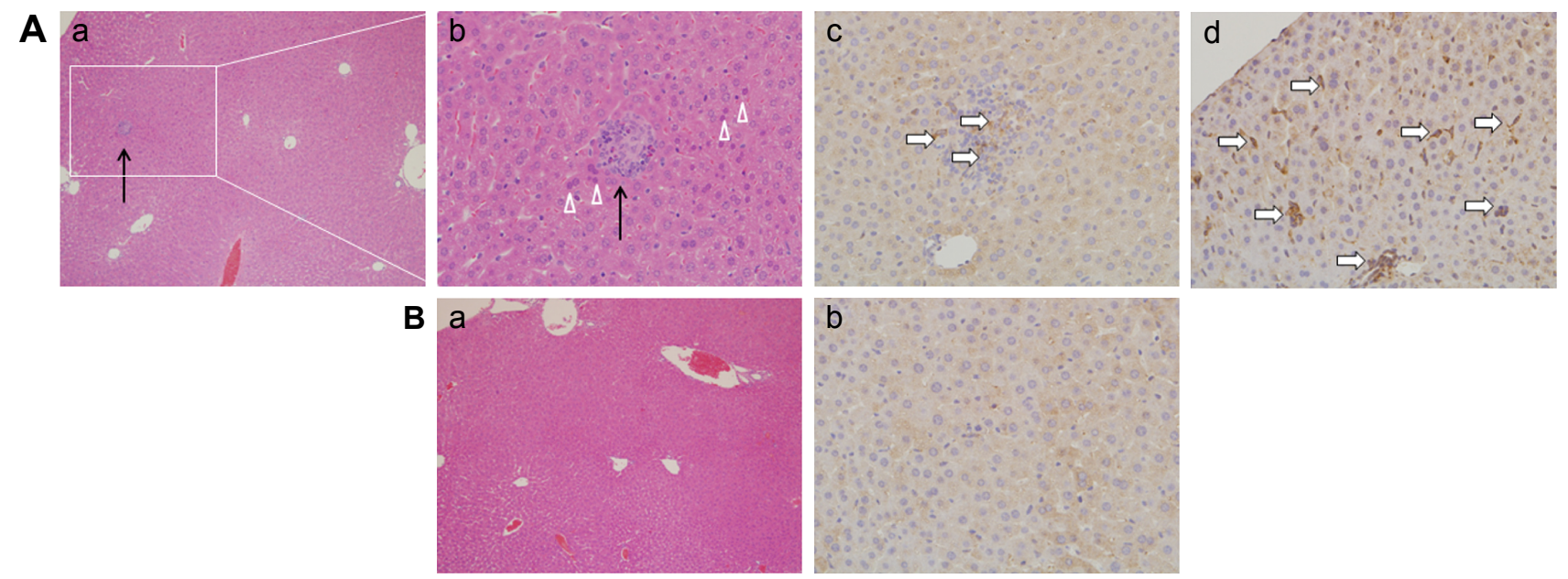

Figure 4 Histological observation ( $\mathbf{A a}, \mathbf{A b}, \mathbf{B a}$ ) and immunohistochemical staining ( $\mathbf{A c}, \mathbf{A d}, \mathbf{B b}$ ) of macrophage surface molecular marker $\mathrm{F} 4 / 80$ in hepatic tissue sections. Notes: (A) Experimental group (35 mg/kg dosage group); (B) control group (saline-treated group). Magnifications: (a) I00×; (b-d) 400x. Black arrows indicate the diffuse lymphocytic aggregation. White triangles show the focal necrosis of cells. White arrows point to the F4/80 positive cells. 


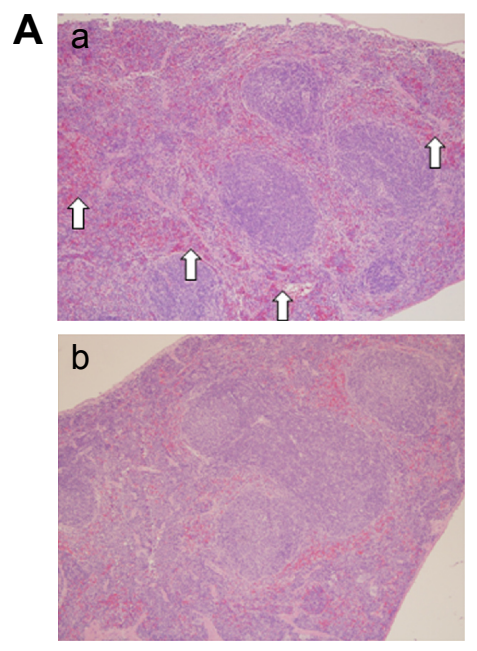

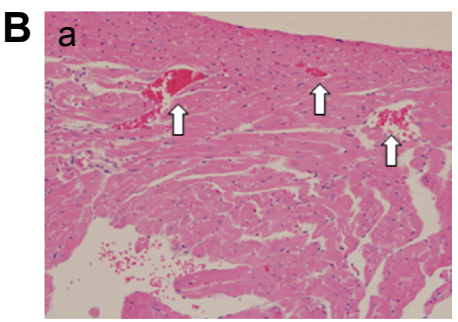

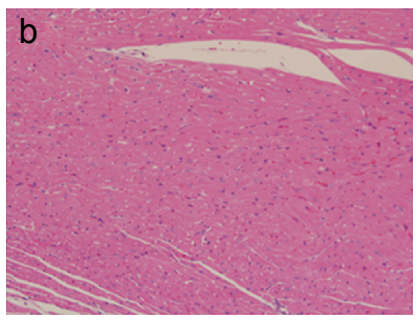

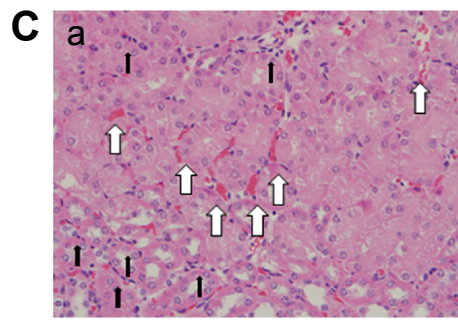

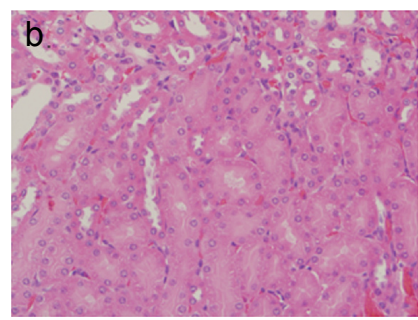

Figure 5 Histological observation of splenic (A), cardiac (B), and nephrotic (C) tissue sections.

Notes: Magnifications: (A) 100×; (B) 200x; (C) 400×. (a) Experimental group (35 mg/kg dosage group); (b) control group (saline-treated group). Spleen, heart, and kidney show hyperemia (white arrow), whereas the kidney shows inflammatory cell infiltration (black arrow) in comparison to the control groups.

dose-dependent manner, whereas IL-18, TNF- $\alpha$, and IL-6 expression was higher in the treated group than in the control group. The increased expressions of IL-18, TNF- $\alpha$, and IL- 6 did not occur in a dose-dependent manner. The results indicated systemic inflammation in the SiNP-treated groups.

\section{The clinical chemistry parameters altered following SiNP treatment}

Changes in the clinical chemistry parameters in serum were tested following the administration of SiNPs (Table 2). Aspartate aminotransferase, creatinine, and uric acid levels were reduced, whereas blood urea nitrogen was increased in the SiNP group, when compared with the control group.
There were some variations among the groups treated with different dosages, but a dose-dependent effect was not observed.

\section{Dose-dependent cytotoxicity induced by SiNPs and the related mechanisms}

The cell viability of RAW264.7 cells was determined using a WST-8 cell counting kit-8 after exposure to 5, 10, 20, and $40 \mu \mathrm{g} / \mathrm{mL}$ SiNPs for $24 \mathrm{~h}$. As shown in Figure 8A, $5 \mu \mathrm{g} / \mathrm{mL}$ of SiNPs promoted the proliferation of the cells as seen by the fast growth of macrophages following stimulation by external factors, but the higher dosages inhibited cell viability and exhibited cytotoxicity. When the dosage increased to
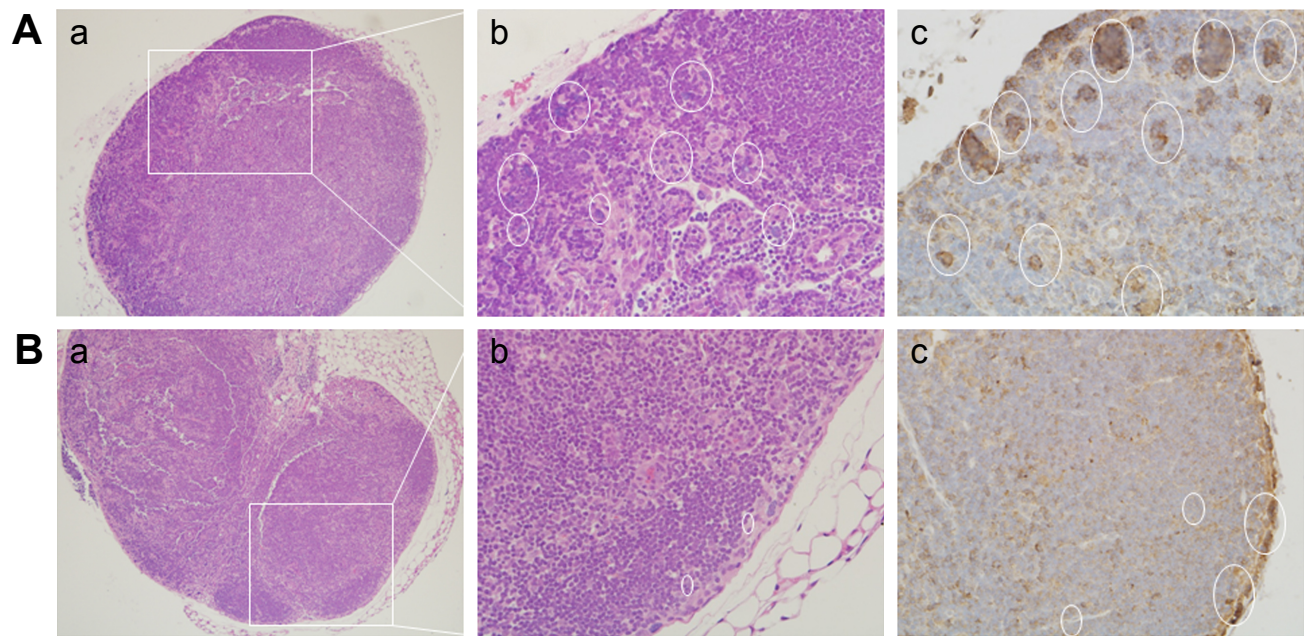

Figure 6 Histological observation (a, b) and immunohistochemical staining (c) of F4/80 in lymph node tissue sections.

Notes: (A) Experimental group (35 mg/kg dosage group); (B) control group (saline-treated group). Magnifications: (a) 100x; (b, c) 400×. White ovals indicate F4/80 positive cells. The white panes indicate amplified fields. 
A

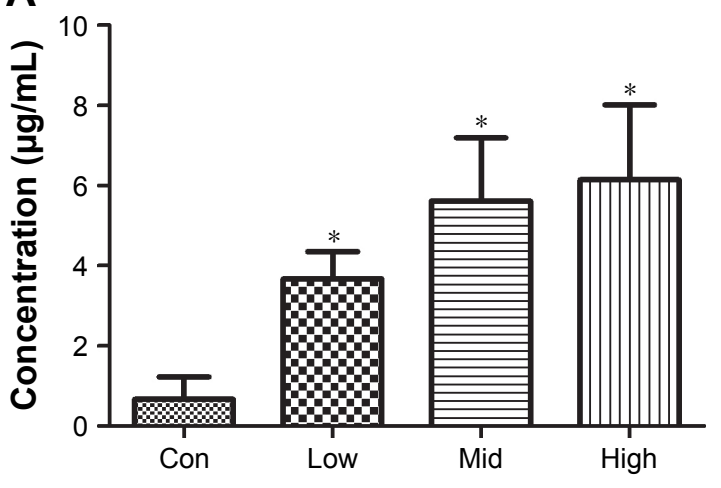

C

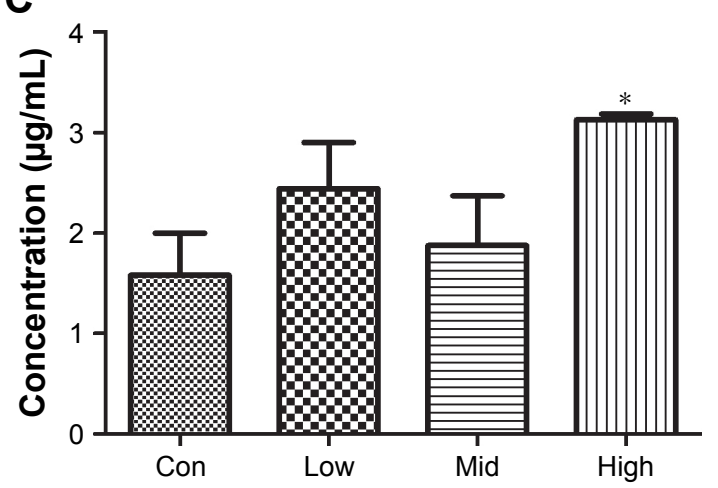

B

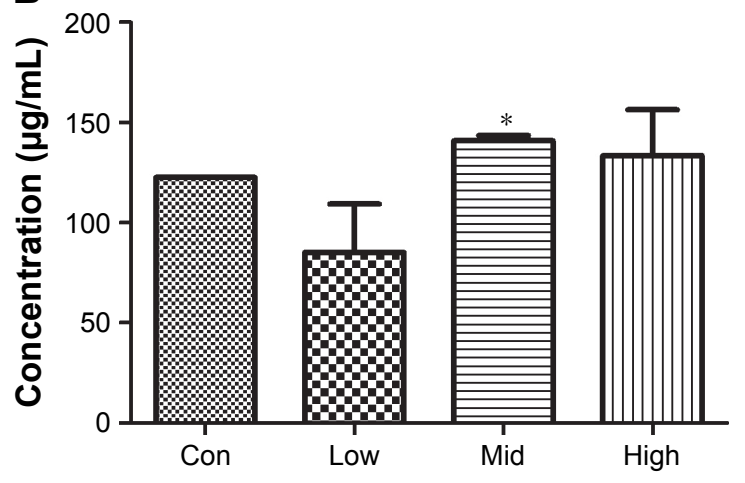

D

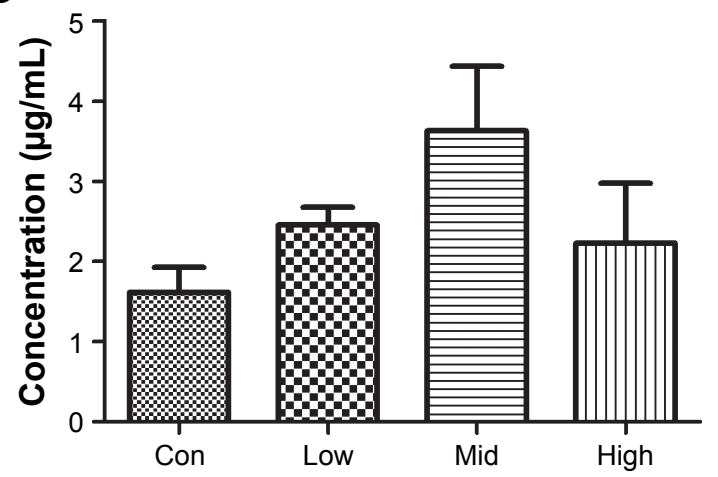

Figure 7 The expression of inflammatory cytokines in serum after the administration of silica nanoparticles.

Notes: (A) IL-I $\beta$; (B) IL-I8; (C) TNF- $\alpha$; (D) IL-6. The serum samples were collected after the administration of SiNPs at different dosages (low: 7 mg/kg, mid: 2 I mg/kg, high: $35 \mathrm{mg} / \mathrm{kg}$, and saline for the control group [Con]). Data are expressed as mean \pm standard deviation and $\mathrm{n}=4$. $* \mathrm{P}<0.05$ compared with the control group.

Abbreviations: IL, interleukin; TNF, tumor necrosis factor.

$40 \mu \mathrm{g} / \mathrm{mL}$, almost half of the cells died. Morphological observation of the cells revealed a similar tendency (Figure 8C).

The neutral red method was used to detect the phagocytic ability of the RAW264.7 cells. In Figure 8B, the ingestion of neutral red dyestuff increased at $5 \mu \mathrm{g} / \mathrm{mL}$ and decreased with increasing dosage up to $10 \mu \mathrm{g} / \mathrm{mL}$ in a dose-dependent manner.
When cells died, the ability of phagocytosis weakened; these results are in agreement with the cell viability tests.

The primary function of macrophages is to mediate inflammation. To explore the underlying mechanisms, the inflammation-related proteins were tested by Western blot. As shown in Figure 8D, the inflammasome proteins NLRP3,

Table 2 Effect of silica nanoparticles on the clinical chemistry parameters of liver and kidney function

\begin{tabular}{|c|c|c|c|c|}
\hline & Control & Low & Med & High \\
\hline TP $(g / L)$ & $71.67 \pm 4.02$ & $73.37 \pm 5.98$ & $72.62 \pm 1.46$ & $74.05 \pm 4.69$ \\
\hline GLO (g/L) & $36.37 \pm 2.00$ & $37.67 \pm 4.23$ & $36.35 \pm 1.27$ & $37.70 \pm 3.59$ \\
\hline ALB (g/L) & $35.30 \pm 2.07$ & $35.70 \pm 1.88$ & $36.27 \pm 0.81$ & $36.35 \pm 1.68$ \\
\hline ALB/GLO & $0.97 \pm 0.02$ & $0.98 \pm 0.02$ & $1.00 \pm 0.04$ & $0.97 \pm 0.08$ \\
\hline ALT (IU/L) & $20.25 \pm 3.71$ & $19.75 \pm 0.85$ & $17.63 \pm 1.14$ & $20.55 \pm 3.49$ \\
\hline AST (IU/L) & $84.77 \pm 12.68$ & $68.73 \pm 2.06$ & $58.17 \pm\left. 10.5\right|^{\mathrm{b}, *}$ & $75.53 \pm 6.64^{\mathrm{b}, *}$ \\
\hline $\mathrm{LDH}(\mathrm{U} / \mathrm{L})$ & $568.37 \pm 91.54$ & $533.65 \pm 145.58$ & $509.32 \pm 180.39$ & $301.40 \pm 41.17$ \\
\hline BUN (mmol/L) & $5.47 \pm 1.25$ & $7.28 \pm 0.55^{\mathrm{a}, *}$ & $7.31 \pm 0.20^{\mathrm{a}, *}$ & $6.94 \pm 0.17^{\mathrm{c}, *}$ \\
\hline $\mathrm{Cr}(\mathrm{mmol} / \mathrm{L})$ & $12.07 \pm 1.77$ & $7.47 \pm 0.85^{c, *}$ & $10.87 \pm 1.56^{\mathrm{d}, *}$ & $8.85 \pm 3.70$ \\
\hline $\mathrm{CA}(\mu \mathrm{mol} / \mathrm{L})$ & $92.75 \pm 10.11$ & $86.25 \pm 4.11$ & $80.00 \pm 3.6 I^{c, *}$ & $115.00 \pm 18.52^{\mathrm{d}, *}$ \\
\hline
\end{tabular}

Notes: Data are presented as mean $\pm \mathrm{SD}, \mathrm{n}=4$. Low, $7 \mathrm{mg} / \mathrm{kg}$ dosage; med, $2 \mathrm{l} \mathrm{mg} / \mathrm{kg}$ dosage; high, $35 \mathrm{mg} / \mathrm{kg}$ dosage. ${ }^{\mathrm{a}} \mathrm{P}<0.0 \mathrm{l}$, compared with the control group; ${ }^{\mathrm{b}} \mathrm{P}<0.05$, compared with the med group using one-way ANOVA; $\mathrm{c}<<0.05$; $\mathrm{d} P<0.05$, compared with the low group. *Significant differences.

Abbreviations: ANOVA, analysis of variance; TP, total protein; GLO, globulin; ALB, albumin; ALT, alanine aminotransferase; AST, aspartate aminotransferase; LDH, lactic dehydrogenase; BUN, blood urea nitrogen; $\mathrm{Cr}$, creatinine; $\mathrm{CA}$, uric acid. 
A
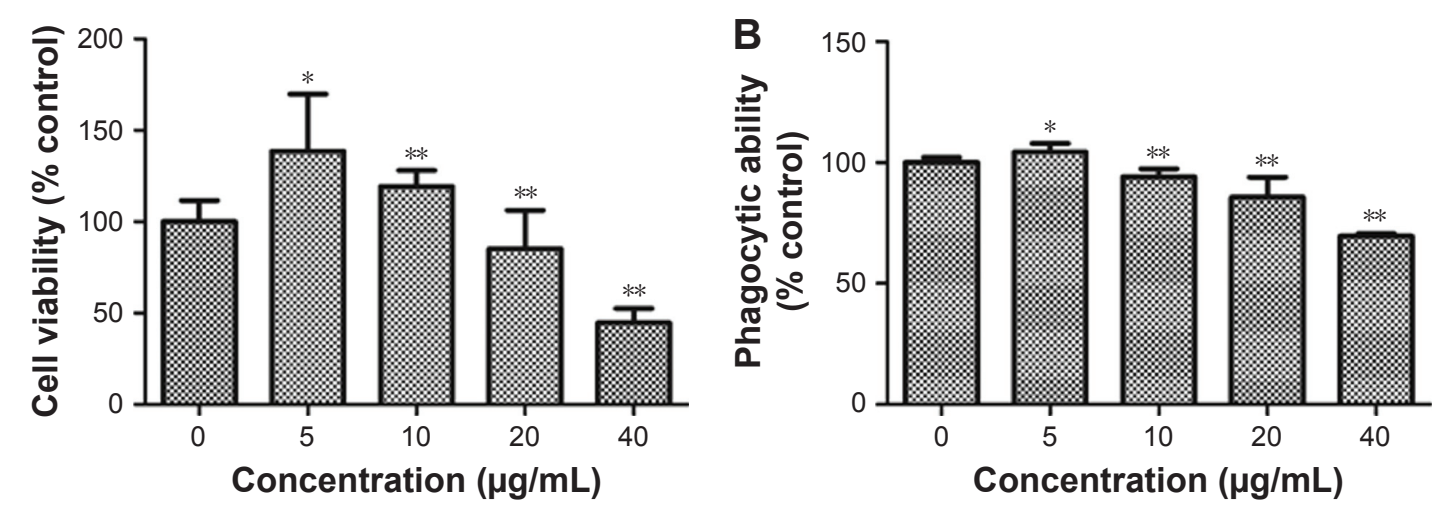

C
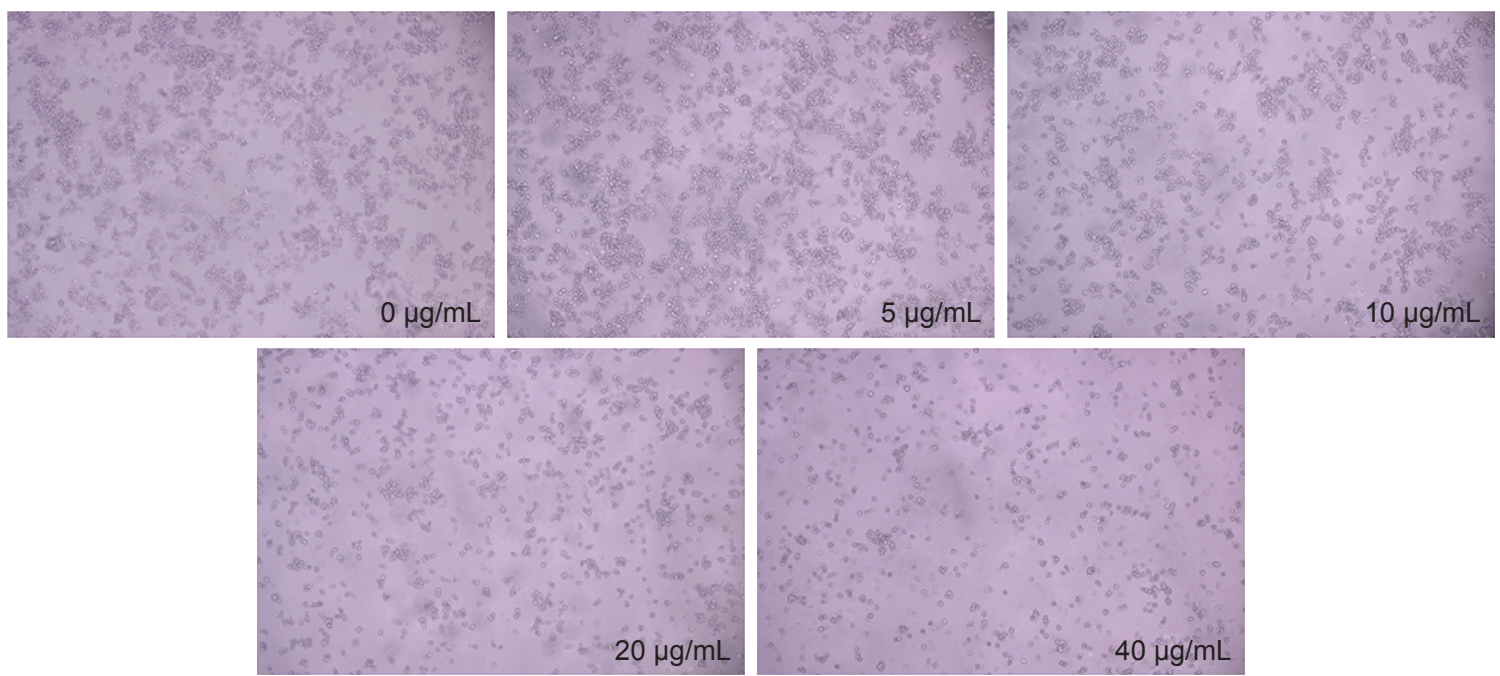

D
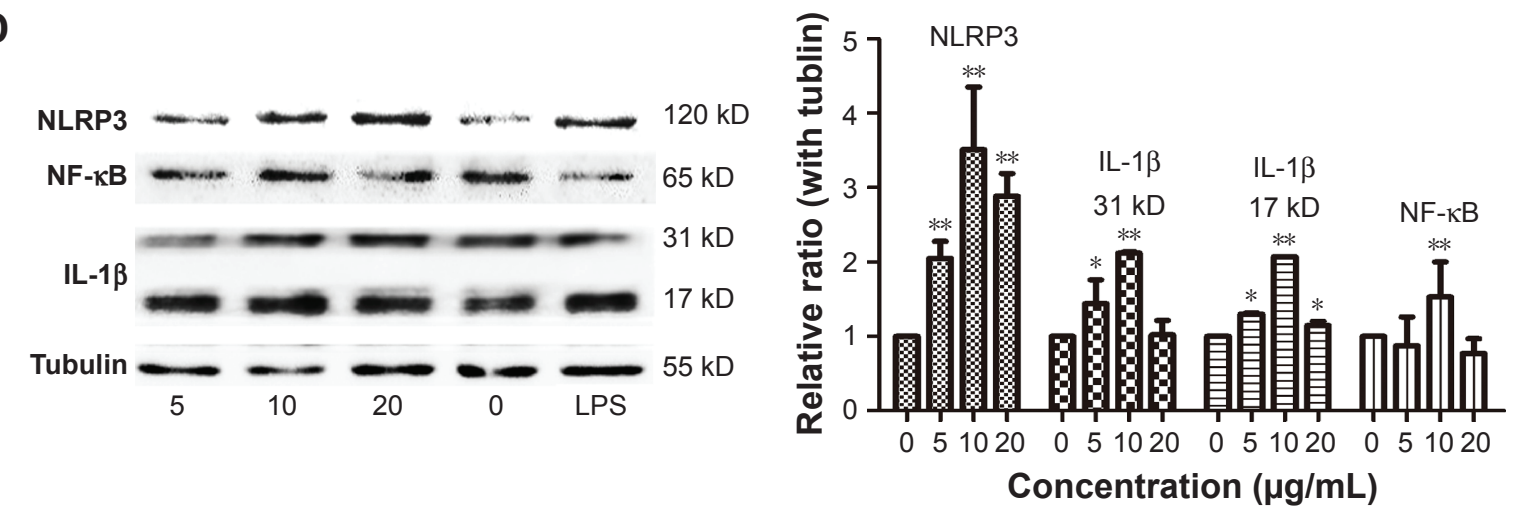

Figure 8 Cytotoxicity of RAW264.7 cells induced by silica nanoparticles and the expression of inflammation-related proteins detected by Western blot after 24-hour exposure to silica nanoparticles at different concentrations.

Notes: (A) Cell viability; (B) the phagocytic function changing; (C) cell growth status observed using light microscopy (I00x); (D) Western blot analysis of NLRP3, NF-kB, and IL-I $\beta$; the group of lipopolysaccharide (LPS) used as positive control, and tubulin was used as the internal control. The viability and phagocytic ability of RAW264.7 cells increased at low dose $(5 \mu \mathrm{g} / \mathrm{mL})$ followed by a dose-dependent decrease in agreement with the morphological observations. Inflammatory protein expression increased but was not dependent on dosage. Data are expressed as mean \pm standard deviation from three independent assays. $* P<0.05$ and $* * P<0.01$ compared with the control group $(0 \mu \mathrm{g} / \mathrm{mL})$.

Abbreviations: NF, necrosis factor; IL, interleukin.

IL-1 $\beta$, and necrosis factor- $\kappa \mathrm{B}$ were highly expressed in the SiNP-treated group.

\section{Discussion}

The toxicological evaluation of SiNPs is necessary for the safety of human beings. This study aimed to analyze the mechanisms of inflammation induced by SiNPs through the respiration pathway. Repeated dose toxicity studies were performed herein as most in vivo reports previously published have focused on acute toxicity ${ }^{16,17}$ and do not provide an indication of the toxic effects in the longer term. The histopathology and ultrastructure variations of some 
primary organs were analyzed and the clinical parameters were tested, followed by an exploration of the underlying mechanism using a macrophage cell line in vitro. Three SiNP dosages were used; however, considering that all SiNPtreated groups showed similar phenomena, in the TEM and histopathological studies only the control and the highest dosage groups were discussed.

TEM images exhibited an ultrastructural variation following the administration of SiNPs. An effect of SiNPs on the organelles in the lung, liver, and heart was observed. SiNPs were located in the lysosomes of macrophages in the lung of the experimental group (Figure 2). Once the SiNPs entered the cell, they were engulfed in the membrane-bound vesicles and were subsequently evolved into lysosomes. ${ }^{18}$ The SiNPs were located in lysosomes or membrane-bound vesicles around the nucleus, and a swelling of mitochondria in the SiNP-treated group was observed (Figure 2A). Previous studies have reported the same phenomenon in vivo or in vitro. ${ }^{10-15}$ The mitochondria were observed to be more susceptible than other organelles. In the heart and liver of the SiNP-treated group, more secondary lysosomes were observed than in the control group. Lysosomes play an important role in cell physiology, including in the degradation of exogenous elements or of endogenous damaged organelles, as well as in nutrient signaling and regulation of cell growth. ${ }^{19}$ The presence of a large number of secondary lysosomes may indicate the unstable status of the tissues. Previous studies have shown that nanoparticles can penetrate organs following ingestion, injection, skin application, or inhalation through systemic circulation. ${ }^{7,16,17}$ Herein, SiNPs may have been transported into other organs, but there was no obvious evidence of this having occurred. However, SiNPs in the lung may have induced the secretion of inflammatory factors, thus affecting systemic and other tissues' reactions.

The histology results provided an indication of the pathological status of the organs. In the lung of the SiNP-treated group, tissue damage was observed, including alveolar consolidation areas, wide alveolar septa, alveolar wall congestion, and lymphocyte and macrophage infiltration in the pulmonary mesenchyme (Figure 3 ), all of which indicate the occurrence of inflammation in the lung. Previous reports have also shown that the application of SiNPs led to pulmonary inflammation and that the particles were located in alveolar macrophages and in the draining lymph nodes. ${ }^{20,21}$ Herein, the SiNPs were engulfed in macrophages and the number of macrophages in the experimental group was considerably greater than in the control group.
Intravenous injection of SiNPs has been shown to cause serious liver damage. ${ }^{22}$ In this study, granuloma-like lymphocytic infiltration and focal hepatocyte necrosis appeared in the liver, which resulted from the adiminstration of SiNPs through the respiration pathway. Furthermore, the number of macrophages was greater in the SiNP-treated group, indicating that SiNPs could induce liver inflammation through the respiration pathway.

In the spleen and heart, signs of inflammation were observed, including hyperemia and inflammatory cell infiltration. Because the SiNPs can enter blood circulation, it is likely that the particles may reach these organs and trigger the inflammatory response mediated by macrophages. Meaningfully, in the lymph nodes, there were more macrophages in the SiNP-treated group. A previous study indicated that carbon nanoparticles accumulated in the lymph nodes over 90 days following subcutaneous injection. ${ }^{23}$ Lymph nodes have an important function in the immune system - they filter foreign particles and eliminate them through the macrophages - and also play a role in immune response. Herein, the number of macrophages present in the lymph nodes was increased in the SiNP-treated group, despite there being no obvious SiNP accumulation. However, the SiNPs induced local and systemic inflammatory actions and therefore the macrophages may have been recruited and circulated by blood and lymph circulation. Although the acute toxicity of SiNPs had already been described, ${ }^{17,24}$ this study reveals that the inflammation may be sustained for a longer period and that the macrophages play a pivotal role in local and systemic inflammation.

Systemic inflammation was assessed through the expression of related cytokines. IL-1 $\beta$ levels were significantly increased in the SiNP-treated groups in a dose-dependent manner (Figure 7). Furthermore, the release of IL-18, TNF- $\alpha$, and IL-6 was much higher than in the control group, but did not increase in a dose-dependent manner. Certain factors were related to the secretions of inflammatory cytokines, with time being the most important one. A previous study about carbon nanotubes found that 2 days following injection the cytokines changed significantly, whereas most returned to approximately normal levels after 7 days. ${ }^{23}$ The changes of serum cytokine level in this study suggested that the inflammatory reaction was actively induced by the SiNPs.

To determine the hepatic and nephric effects induced by SiNPs, the clinical parameters of liver and kidney function were examined, with the results confirming effects of these two organs. Aspartate aminotransferase levels decreased following the administration of SiNPs, indicating the variation of hepatic function, although this was not in a 
dose-dependent manner. Serum levels of blood urea nitrogen increased, whereas creatinine levels decreased and uric acid levels oscillated in the SiNP-treated groups, indicating nephric toxicity. All of the observed variations were in accordance with pathological observations. Clinical chemistry parameters may have been affected by various factors, yet certain hepatic function indices remained unchanged, likely due to the tested time point.

The intensive mechanism of inflammation was explored by in vitro study using the RAW264.7 cell line of mouse macrophages. The cell proliferation and phagocytic abilities of macrophages, and the accompanying cell morphological changes and molecular mechanisms, were assessed. Following treatment with different concentrations of SiNPs, the number of macrophages increased in the low-dose exposure and decreased when the dosages increased. As macrophages are defense cells, once the exogenous materials appear, the macrophages grow rapidly and secrete inflammatory factors. However, when the amount of the exogenous substance increases, the macrophages will be damaged or dead. The results of cell viability and phagocytic ability verified such a macrophage reaction to the SiNPs. The light microphotographs also showed the variation of the cell contacted with the nanoparticles. The detection of the molecular contents indicated that the underlying mechanism was one of inflammatory reaction. Following the administration of SiNPs, the levels of NLRP3 augmented and the secretion of IL-1 $\beta$ increased. NLRP3 and IL-1 $\beta$ are the key molecules in the innate immune system to protect against foreign particles and promote the inflammatory response..$^{25-27}$ The NLRP3 inflammasome is a multiprotein platform that contains mainly the Nod-like receptor protein NLRP3, apoptosis-associated speck-like protein containing C-terminal caspase recruitment, and caspase-1. Once the NLRP3 inflammasome is active, the precursor IL-1 $\beta$ $(31 \mathrm{kD})$ is cleaved to the mature type $(17 \mathrm{kD})$. The secretion of $\mathrm{IL}-1 \beta$ is a proinflammatory mediator involved in systemic and local inflammation. ${ }^{28}$ Nevertheless, the mechanism for NLRP3 activation and IL-1 $\beta$ secretion remains unclear. Previous reports have proposed that the reactive oxygen species-related signal pathway might play a critical role in the activation of NLRP3. ${ }^{29,30}$ Thus, we tested NF- $\kappa B$ expression, with the results revealing a large amount of NF- $\kappa B$ in the SiNP-treated groups (Figure 7D). These results indicate that SiNPs could affect the proliferation ability of macrophages, stimulate and disrupt phagocytic function, and alter cell morphology. Meanwhile, the inflammation-related NLRP3 inflammasome activation and the high expression of NF- $\kappa \mathrm{B}$ brought the inflammatory reaction inside of the macrophages.

\section{Conclusion}

The present study confirms the toxicity of SiNPs in vivo following intratracheal instillation. SiNPs induced local and systemic inflammation. Most of the SiNPs were engulfed by the macrophages and located in the lysosomes in the lung. Macrophages in the organs, lymph nodes, and blood circulation may play a critical role in inflammatory reactions. The endocellular mechanisms induced by SiNPs are possibly involved in NLRP3 inflammasome excitation and NF- $\kappa \mathrm{B}$ signal pathway activation. However, more studies need to be performed to further elucidate the underlying mechanisms. The results in this article may offer essential information for the safety evaluation of SiNPs and provide guidance for the application of SiNPs in nanomedicine.

\section{Acknowledgments}

This work was supported by National Natural Science Foundation of China (NSFC) (No 81402709, No 81402710, and No 81202608).

\section{Disclosure}

The authors report no conflicts of interest in this work.

\section{References}

1. Keller AA, McFerran S, Lazareva A, Suh S. Global life cycle releases of engineered nanomaterials. J Nanopart Res. 2013;15(6):1-17.

2. IARC (1997). Silica, some silicates, coal dust and para-aramid fibrils, IARC Monographs on the Evaluation of Carcinogenic Risks to Humans, Vol. 68, World Health Organization, Geneva, Switzerland.

3. Organisation for Economic Co-operation and Development (OECD): List of Manufactured Nanomaterials and List of Endpoints for Phase One of the Sponsorship Programme for the Testing of Manufactured Nanomaterials: Revision, Series on the Safety of manufactured nanomaterials No. 27-ENV/JM/MONO (2010)46; 2010. Available from: http:// www.oecd.org/science/nanosafety/publicationsintheserie sonthesafetyofmanufacturednanomaterials.htm. Accessed October 27, 2016.

4. Guadagnini R, Moreau K, Hussain S, Marano F, Boland S. Toxicity evaluation of engineered nanoparticles for medical applications using pulmonary epithelial cells. Nanotoxicology. 2015;9(Suppl 1): $25-32$.

5. Isabelle G, Grégoire N, Sonja B, et al. Metallic oxide nanoparticle translocation across the human bronchial epithelial barrier. Nanoscale 2015;7(10):4529-4544.

6. Maser E, Schulz M, Sauer UG, et al. In vitro and in vivo genotoxicity investigations of differently sized amorphous $\mathrm{SiO} 2$ nanomaterials. Mutat Res Genet Toxicol Environ Mutagen. 2015;794:57-74.

7. Napierska D, Thomassen LC, Lison D, Martens JA, Hoet PH. The nanosilica hazard: another variable entity. Part Fibre Toxicol. 2010;7(1) 242-248.

8. Bancos S, Stevens DL, Tyner KM. Effect of silica and gold nanoparticles on macrophage proliferation, activation markers, cytokine production, and phagocytosis in vitro. Int J Nanomed. 2015;10:183-206.

9. Delaval M, Boland S, Solhonne B, et al. Acute exposure to silica nanoparticles enhances mortality and increases lung permeability in a mouse model of Pseudomonas aeruginosa pneumonia. Part Fibre Toxicol. 2015;12:1. 
10. Xue Y, Chen Q, Ding T, Sun J. SiO(2) nanoparticle-induced impairment of mitochondrial energy metabolism in hepatocytes directly and through a Kupffer cell-mediated pathway in vitro. Int $J$ Nanomed. 2014;9:2891-2903.

11. Du Z, Zhao D, Li J, et al. Cardiovascular toxicity of different sizes amorphous silica nanoparticles in rats after intratracheal instillation. Cardiovasc Toxicol. 2013;13(3):194-207.

12. Yoshida T, Yoshioka Y, Tochigi S, et al. Intranasal exposure to amorphous nanosilica particles could activate intrinsic coagulation cascade and platelets in mice. Part Fibre Toxicol. 2013;10(3):1-12.

13. Guichard Y, Maire MA, Sébillaud S, et al. Genotoxicity of synthetic amorphous silica nanoparticles in rats following short-term exposure, part 2: intratracheal instillation and intravenous injection. Environ $\mathrm{Mol}$ Mutagen. 2014;56(2):2962-2966.

14. Katsuhiro I, Eriko T, Yoshimi S, Kanae S, Isao I, Masakatsu T. Liver injury induced by thirty- and fifty-nanometer-diameter silica nanoparticles. Biol Pharm Bull. 2013;36(3):370-375.

15. Yu Y, Li Y, Wang W, et al. Acute toxicity of amorphous silica nanoparticles in intravenously exposed ICR mice. PloS One. 2013;8(4): e61346.

16. Li L, Liu T, Fu C, Tan L, Meng X, Liu H. Biodistribution, excretion, and toxicity of mesoporous silica nanoparticles after oral administration depend on their shape. Nanomed Nanotechnol Biol Med. 2015;11(8): 1915-1924.

17. Nemmar A, Yuvaraju P, Beegam S, Yasin J, Kazzam EE, Ali BH. Oxidative stress, inflammation, and DNA damage in multiple organs of mice acutely exposed to amorphous silica nanoparticles. Int J Nanomed. 2016;11:919-928.

18. Chu Z, Zhang S, Zhang B, et al. Unambiguous observation of shape effects on cellular fate of nanoparticles. Sci Rep. 2014;4(3):4495.

19. Schutz I, Lopez-Hernandez T, Gao Q, et al. Lysosomal dysfunction caused by cellular accumulation of silica nanoparticles. J Biol Chem. 2016;291(27):14170-14184.
20. Landsiedel R, Ma-Hock L, Hofmann T, et al. Application of short-term inhalation studies to assess the inhalation toxicity of nanomaterials. Part Fibre Toxicol. 2014;11:16.

21. Roberts JR, Mercer RR, Chapman RS, et al. Pulmonary toxicity, distribution, and clearance of intratracheally instilled silicon nanowires in rats. J Nanomater. 2012;2012:398302.

22. Li T, Cheng J. Nonporous silica nanoparticles for nanomedicine application. Nano Today. 2013;8(3):290-312.

23. Meng J, Yang M, Jia F, Xu Z, Kong H, Xu H. Immune responses of $\mathrm{BALB} / \mathrm{c}$ mice to subcutaneously injected multi-walled carbon nanotubes. Nanotoxicology. 2011;5(4):583-591.

24. Nemmar A, Albarwani S, Beegam S, et al. Amorphous silica nanoparticles impair vascular homeostasis and induce systemic inflammation. Int J Nanomed. 2014;9:2779-2789.

25. Baron L, Gombault A, Fanny M, et al. The NLRP3 inflammasome is activated by nanoparticles through ATP, ADP and adenosine. Cell Death Dis. 2015;6(2):e1629.

26. Matsuo J, Nakamura S, Takeda S, et al. Synergistic costimulatory effect of Chlamydia pneumoniae with carbon nanoparticles on NLRP3 inflammasome-mediated IL-1 $\beta$ secretion in macrophages. Infect Immun. 2015;83(7):2917-2925.

27. Sun B, Wang X, Ji Z, et al. NADPH oxidase-dependent NLRP3 inflammasome activation and its important role in lung fibrosis by multiwalled carbon nanotubes. Small. 2015;11(17):2087-2097.

28. Schroder K, Tschopp J. The inflammasomes. Cell. 2010;140(6): $821-832$.

29. Joshi S, Wang W, Peck AB, Khan SR. Activation of the NLRP3 inflammasome in association with calcium oxalate crystal induced reactive oxygen species in kidneys. J Urol. 2015;193(5):1684-1691.

30. Jung HJ, Pak PJ, Park SH, et al. Silver wire amplifies the signaling mechanism for IL-1beta production more than silver submicroparticles in human monocytic THP-1 cells. PloS One. 2014;9(11):e112256.
International Journal of Nanomedicine

\section{Publish your work in this journal}

The International Journal of Nanomedicine is an international, peerreviewed journal focusing on the application of nanotechnology in diagnostics, therapeutics, and drug delivery systems throughout the biomedical field. This journal is indexed on PubMed Central, MedLine, CAS, SciSearch $®$, Current Contents ${ }^{\circledR} /$ Clinical Medicine,

\section{Dovepress}

Journal Citation Reports/Science Edition, EMBase, Scopus and the Elsevier Bibliographic databases. The manuscript management system is completely online and includes a very quick and fair peer-review system, which is all easy to use. Visit http://www.dovepress.com/ testimonials.php to read real quotes from published authors. 